\title{
Biologia reprodutiva de Palicourea macrobotrys Ruiz \& Pavon (Rubiaceae): um possível caso de homostilia no gênero Palicourea Aubl.
}

\author{
CHRISTIANO P. COELHO ${ }^{1,2}$ e ANA ANGÉLICA A. BARBOSA ${ }^{1}$
}

(recebido: 26 de dezembro de 2002; aceito: 14 de agosto de 2003)

\begin{abstract}
Reproductive biology of Palicourea macrobotrys Ruiz \& Pavon (Rubiaceae): a possible case of homostyly in the genus Palicourea Aubl.). The genus Palicourea Aubl. (Rubiaceae) is restricted to the neotropics and includes approximately 200 species of shrubs and small trees. Flowers are mostly distylous, colored, odorless and tubular in cymose inflorescences and usually pollinated by hummingbirds. Homostyly is a rare condition in the genus. The objective of this study is to characterize the reproductive biology of Palicourea macrobotrys Ruiz \& Pavon, the pollination biology and identifying the breeding system. The study was carried out in the Panga Ecological Station, Uberlândia, MG (19¹1'10" S and 48²4'35" W), from May 2000 to May 2001. The species bloomed from December to June, and fruits were produced in March. It presented inflorescences with ca. 60 hermaphrodite, pentamerous, isostemous and homostylous flowers. Flowers opened between 5:00 and 7:00 h and last 14 hours. Nectar production was small $(6.86 \mu \mathrm{L})$ with a mean concentration of sugars of $18 \%$. The floral visitors were ants, small bees, butterflies and hummingbirds, which were active mainly in the morning, between 7:00 and 12:00 h. The hummingbird Thalurania furcata was considered the main pollinator due to its visiting behavior and frequency of visits. The species is self-compatible, and the pollen tubes reached the ovary four hours after self and cross pollinations.
\end{abstract}

Key words - homostyly, Palicourea, pollination, reproductive biology, Rubiaceae

RESUMO - (Biologia reprodutiva de Palicourea macrobotrys Ruiz \& Pavon (Rubiaceae): um possível caso de homostilia no gênero Palicourea Aubl.). O gênero Palicourea Aubl. (Rubiaceae) é restrito aos neotrópicos e inclui aproximadamente 200 espécies de arbustos ou pequenas árvores, que produzem flores tubulares, coloridas e sem odor, dispostas em inflorescências paniculadas e polinizadas por beija-flores, sendo quase todas as espécies distílicas. Homostilia é uma condição rara no gênero. O objetivo do estudo foi caracterizar a biologia reprodutiva de Palicourea macrobotrys Ruiz \& Pavon e sua biologia de polinização, avaliando o sistema reprodutivo. O estudo foi desenvolvido na Estação Ecológica do Panga, município de Uberlândia, MG (19 11'10" S e 48 24'35' W), entre os meses de maio de 2000 e maio de 2001 . A espécie floresceu de dezembro a junho, e frutificou a partir de março; apresenta inflorescências com cerca de 60 flores hermafroditas, pentâmeras, isostêmones e homostílicas. A flor abre entre 5:00 e 7:00 h e dura cerca de 14 horas. O volume de néctar produzido é de 6,86 $\mu \mathrm{L}$, com concentração média de açúcares de $18 \%$. Os visitantes florais observados foram formigas, uma espécie de abelha, borboletas e beija-flores, principalmente no período da manhã, entre 7:00 e 12:00 h. O beija-flor Thalurania furcata foi considerado o principal polinizador devido ao seu comportamento na flor e freqüência de visitas. A espécie é autocompatível, sendo que os tubos polínicos atingem o ovário quatro horas após as autopolinizações e as polinizações cruzadas.

Palavras-chave - biologia reprodutiva, homostilia, Palicourea, polinização, Rubiaceae

\section{Introdução}

O gênero Palicourea Aubl. pertence à tribo Psychotrieae da família Rubiaceae e compreende cerca de 200 espécies de arbustos e pequenas árvores distribuídos somente nos trópicos do Novo Mundo (Taylor 1997). Essas espécies são tipicamente membros do sub-bosque de matas tropicais e poucas delas ocorrem em savanas (Taylor 1997). Existem três centros de riqueza de espécies de Palicourea, todos na América

\footnotetext{
1. Universidade Federal de Uberlândia, Instituto de Biologia, Pós-graduação em Ecologia e Conservação de Recursos Naturais, Caixa Postal 593, 38400-902 Uberlândia, MG, Brasil.

2. Autor para correspondência: cpcbio@hotmail.com
}

do Sul, sendo um deles a região do Planalto Centro-Sul do Brasil, com cerca de 37 espécies (Taylor 1989, 1997). Esse gênero apresenta flores com corola tubular, sem odor, de cores fortes e polinizadas principalmente por beija-flores, e os frutos carnosos, azuis a púrpuras e dispersos por aves (Taylor 1997). A maioria das espécies é distílica, uma condição considerada ancestral no gênero (Taylor 1997).

A distilia é um dimorfismo floral controlado geneticamente, caracterizado pela separação espacial recíproca entre altura de filetes e estiletes de dois tipos de flores produzidos por indivíduos diferentes (Richards 1986, Hamilton 1990). Flores com estilete curto e filetes longos são denominadas brevistilas ou "thrum", enquanto as flores com filetes curtos e estiletes longos são denominadas longistilas ou "pin". Associadas a 
essas diferenças entre os dois morfos estão a morfologia da corola, tamanho e número de grãos de pólen e morfologia do estigma (Barrett 1992). Além destes, mais 14 polimorfismos já foram identificados em famílias distílicas, não havendo, geralmente, diferenças nos caracteres vegetativos (Richards 1986, Barrett 1992).

A variação dentro de grupos distílicos tem envolvido derivações em sistemas reprodutivos, como a homostilia (Hamilton 1990, Barret 1992). Homostilia refere-se a flores com anteras e estigmas no mesmo nível e é evolutivamente derivada de plantas distílicas (Hamilton 1990, Barrett 1992). A homostilia é interpretada como resultante de uma recombinação do supergene da distilia (Barrett \& Richards 1990). Richards (1986) verificou que somente indivíduos brevistílicos heterozigotos podem dar origem a indivíduos homostílicos. Podemos encontrar plantas longi-homostílicas, quando anteras e estigmas são longos e brevi-homostílicas, quando anteras e estigma são curtos; longi-homostílicas são muito mais freqüentes do que brevi-homostílicas (Ganders 1979, Sobrevila et al. 1983, Richards 1986). A homostilia está associada à conversão de uma população xenógama, auto-incompatível de plantas distílicas, em uma população autógama autocompatível. Essa mudança no sistema reprodutivo pode ser uma conseqüência evolutiva, levando a uma rápida especiação (Baker 1958, Richards 1986). A homostilia pode aparecer como caráter exclusivo de uma população ou, mais comumente, dentro de uma população distílica, com apenas alguns indivíduos homostílicos (Hamilton 1990).

O presente trabalho tem a finalidade de estudar a fenologia, a morfologia e biologia floral, bem como avaliar o sistema de polinização e reprodução de Palicourea macrobotrys.

\section{Material e métodos}

O estudo foi realizado em um trecho de mata de galeria situado na Estação Ecológica do Panga - EEP (19¹1'10" S e $48^{\circ} 24^{\prime} 35^{\prime} \mathrm{W}$ ), que compreende uma área de 403,85 ha, situada a $30 \mathrm{~km}$ de Uberlândia, $\mathrm{MG}$, pertencente à Universidade Federal de Uberlândia. O clima da região é do tipo Aw, segundo a classificação de Köppen (1948), caracterizado por apresentar inverno frio e seco e verão quente e chuvoso (Rosa et al. 1991).

A população estudada se distribui em uma pequena parte (ca. 1 ha) da mata de galeria da EEP, e apresenta 57 indivíduos com, no máximo, $2,5 \mathrm{~m}$ de altura.
Para os estudos fenológicos, 40 indivíduos adultos de Palicourea macrobotrys foram marcados e acompanhados quinzenalmente, de maio de 2000 a maio de 2001. Foram observadas, para cada indivíduo, seis fenofases: brotação, emissão de botões, floração, desenvolvimento dos frutos, dispersão e caducifolia. Cada fenofase foi descrita por notas de intensidade de 0 a 3 , onde 0 indica ausência da fenofase, 1 , baixa intensidade da fenofase $(1 \%$ a $20 \%)$, 2, média intensidade da fenofase ( $21 \%$ a $60 \%)$, e 3 , alta intensidade da fenofase (61\% a 100\%) (Fournier 1974).

Cada indivíduo foi avaliado pela porcentagem de ramos apresentando determinada fenofase, e pela porcentagem de inflorescências e flores apresentando determinada fenofase, obtendo-se, posteriormente, a média para a população.

Dados morfométricos foram coletados em 40 flores ( 30 indivíduos) sendo efetuadas medidas do comprimento e diâmetro da corola, tamanho das estruturas reprodutivas e seu posicionamento no interior da flor. Foi analisada a posição de anteras e estigma em exsicatas da espécie, depositadas no Herbário da Unicamp (UEC) e no Herbário do Instituto Agronômico de Campinas (IAC). Foram observadas 21 flores de 9 exsicatas provenientes de cinco municípios diferentes, quatro no estado de São Paulo e um no estado de Mato Grosso.

Outras características da biologia floral como cor, presença de odor e número de flores produzidas por inflorescência e por indivíduos foram obtidas através de observações diretas no campo em aproximadamente 30 indivíduos.

O horário de abertura e a longevidade das flores foram definidos após a marcação de 20 flores em pré-antese, em oito indivíduos, observados a partir das 5:00 h até as 19:00 h, com intervalos de 15 minutos entre as observações. A determinação da receptividade estigmática foi testada utilizando-se água oxigenada a 3\% (Kearns \& Inouye 1993), além de observações diretas sobre o horário da separação dos lobos estigmáticos. Foi também observada e avaliada, nesse período, a exposição do pólen.

Determinou-se o diâmetro e a quantidade dos grãos de pólen por flor, usando microscopia óptica e contadores manuais. A proporção de grãos viáveis ( $\mathrm{n}=10$ anteras de indivíduos diferentes), foi avaliada com solução de carmin acético, analisando-se os 200 primeiros grãos no campo de visão de cada lâmina utilizando objetiva com aumento de 10× (Kearns \& Inouye 1993). Foi calculada a proporção entre o número de grãos de pólen e óvulos (razão $\mathrm{P}: \mathrm{O}$ ) de acordo com Cruden (1977).

Para se obter o volume de néctar acumulado, foram ensacadas 60 flores em pré-antese, e por volta das 17:00 h do dia seguinte ao isolamento das flores, foram medidos o volume e a concentração do néctar. Mediu-se, também, a produção do néctar, em intervalos de 2 horas, das 7:00 h às 15:00 h, em 20 flores previamente ensacadas, esgotando-se o néctar de cada flor a cada intervalo. 
Foram realizadas observações e coletas dos visitantes florais (invertebrados) durante todo o período de floração, entre 6:00 h e 18:00 h, totalizando 60 horas de observação (34 h de manhã e $26 \mathrm{~h}$ à tarde), com anotação do comportamento dos visitantes, definindo quanto ao modo de exploração do recurso nas flores, e a capacidade de tocar ou não as partes reprodutivas. Insetos visitantes foram coletados e enviados para identificação. Os beija-flores foram identificados no campo e através de fotografias, utilizando-se as chaves de Grantsau (1989). Cada flor visitada foi considerada como uma visita no caderno de anotações.

O estudo do sistema reprodutivo de Palicourea macrobotrys foi avaliado através de polinizações manuais realizadas em 308 flores de 25 indivíduos. Foram realizados tratamentos de autopolinização manual, autopolinização espontânea, apomixia (retirada das anteras na fase de botão, mantendo a flor ensacada) e polinização cruzada. Outras flores foram marcadas como controle para avaliar a eficiência da polinização natural. O desenvolvimento inicial de frutos, 1 mês após a polinização, foi considerado como sucesso de polinização em todos os tratamentos.

O crescimento de tubo polínico foi observado em 30 pistilos polinizados manualmente (15 de autopolinização e 15 de polinização cruzada) e coletados de 10 indivíduos, em intervalos regulares ( 2,4 e 6 horas), sendo 5 pistilos de cada tratamento por intervalo. Esses pistilos foram submetidos à técnica de coloração de Martin (1959) e observados em microscopia de epifluorescência a fim de acompanhar o crescimento dos tubos polínicos e identificar possíveis barreiras de auto-incompatibilidade.

\section{Resultados}

A emissão de botões e a floração de Palicourea macrobotrys ocorreram no período de maior pluviosidade, de dezembro a junho, com dois picos de intensidade diferentes dentro desse período (figura 1). Os períodos de brotação e caducifolia, bem como o desenvolvimento e dispersão dos frutos, estão explicitados na figura 1 .

As flores de Palicourea macrobotrys estão dispostas em panículas cimosas piramidais e terminais (figura 2A) emitidas entre um par de folhas. As inflorescências apresentaram uma média de $57 \pm 20$ flores por inflorescência e um comprimento de $14,88 \mathrm{~cm}$ $\pm 4,97(\mathrm{n}=30)$. As flores abrem aos poucos, com um máximo de seis flores por inflorescência por dia. $\mathrm{O}$ pedicelo e a raque da inflorescência são avermelhados. A corola é simpétala de coloração amarela com as margens dos lacínios vermelhas, pentâmera, raramente tetrâmera, formando um tubo de consistência rígida (figura 2B) com cerca de 16,05 $\mathrm{mm} \pm 0,65 \mathrm{de}$ comprimento e $3,1 \mathrm{~mm} \pm 0,24$ de abertura. Na região mediana deste tubo há um anel de pêlos longos, que protegem e fecham a câmara nectarífera. As flores são hermafroditas, isostêmones e possuem as anteras e o estigma no mesmo nível dentro da corola (figura 3). $\mathrm{O}$ nectário é epígino, tem forma de disco e se localiza na base do tubo da corola. Não foi detectado odor nas flores.

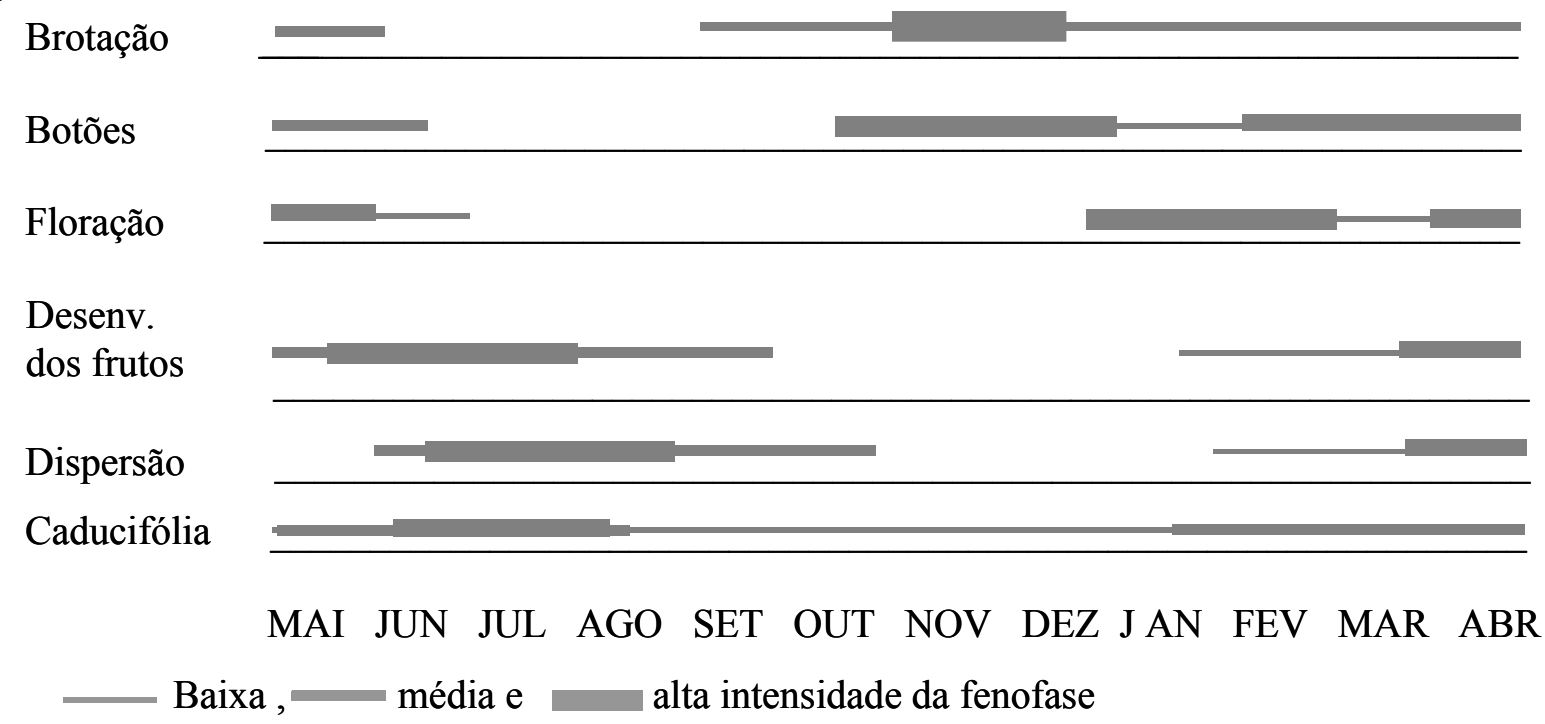

Figura 1. Fenograma de Palicourea macrobotrys, na Estação Ecológica do Panga, Uberlândia, MG.

Figure 1. Phenology of Palicourea macrobotrys, at Panga Ecological Station, Uberlândia, MG. 


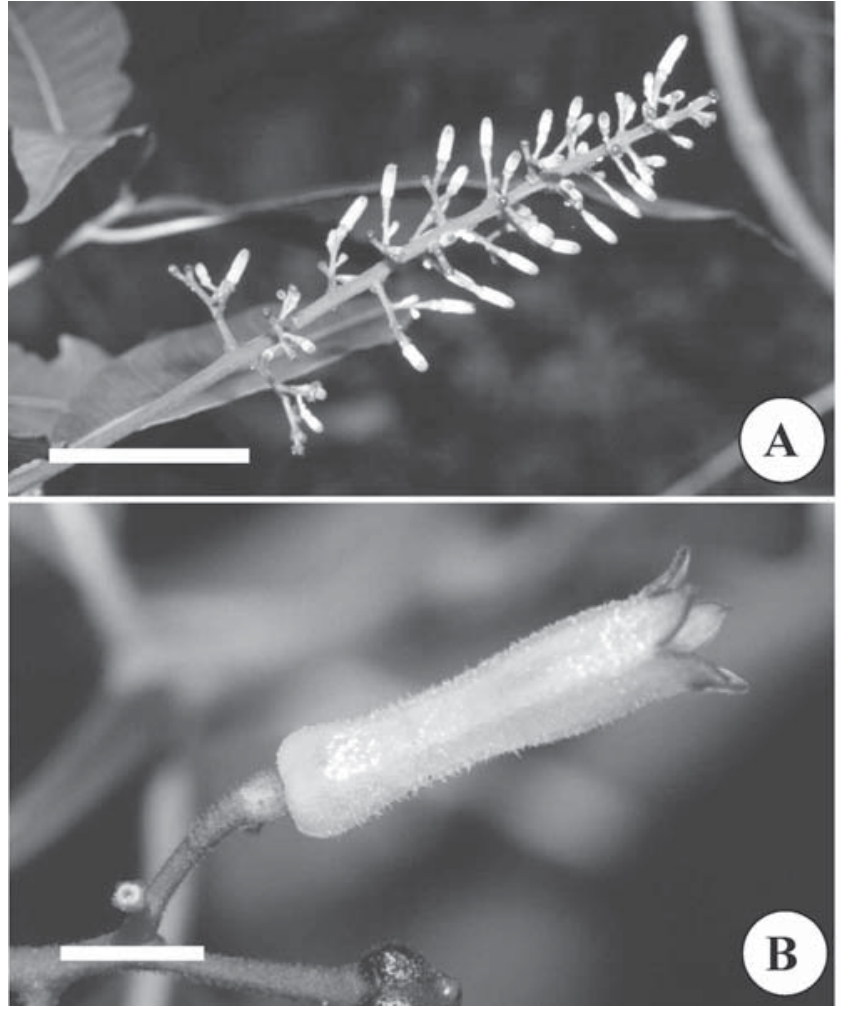

Figura 2. Inflorescência e flor de Palicourea macrobotrys. A. Inflorescência (barra $=50 \mathrm{~mm})$. B. Flor vista lateralmente (barra $=5 \mathrm{~mm})$.

Figure 2. Inflorescence and flower of Palicourea macrobotrys, A. Inflorescence (bar $=50 \mathrm{~mm}$ ); B. Flower, lateral view (bar $=5 \mathrm{~mm}$ ).

O androceu é composto por cinco estames férteis, dialistêmones e epipétalos. Os filetes e as anteras são glabros, amarelados, fundidos até a porção mediana com o tubo da corola, insertos e alternipétalos. As anteras são dorsifixas, bitecas, com cerca de 4,37 $\mathrm{mm} \pm 0,23$ de comprimento $(n=40)$, e possuem deiscência longitudinal, com uma média de $2991 \pm 110,5$ grãos de pólen por flor ( $\mathrm{n}=10$ anteras), com diâmetro dos grãos de pólen de $79,98 \mu \mathrm{m} \pm 3,84$ ( $\mathrm{n}=40$ grãos de 10 anteras de 10 indivíduos diferentes). Em todos os dez indivíduos analisados a viabilidade foi muito alta não havendo variação significativa entre eles $(98,2 \% \pm 2,16$ de grãos de pólen viáveis, $\mathrm{n}=10$ anteras de 10 indivíduos diferentes).

O gineceu possui ovário ínfero (figura 3), bilocular com um óvulo basifixo em cada lóculo. $\mathrm{O}$ estilete e o estigma são amarelados. O estigma é úmido e bífido, abrindo seus lobos quando receptivo. A razão $\mathrm{P} / \mathrm{O}$ foi de $1495,5 \pm 55,2$.
A abertura floral ocorreu no início do amanhecer, entre 5:30 e 7:00 h, e após esse período todas as flores já estavam abertas. O estigma estava receptivo logo após a abertura da flor, permanecendo nessa condição até por volta das 15:00 h. As anteras liberaram pólen logo após a abertura da flor, caracterizando a homogamia. A flor durou entre 13 e 15 horas. As flores abertas permaneceram com uma consistência firme até por volta das 14:00 h, quando a corola começou a perder sua consistência e murchar. Por volta das 19:30 h a flor perdeu a corola, o estilete e o androceu, permanecendo apenas o cálice, o ovário e o disco nectarífero.

A produção de néctar se iniciou antes da antese e persistindo até por volta das 15:00 h. O néctar acumulado no tubo da corola ultrapassou a proteção de pêlos quando não foi retirado. O volume médio de néctar acumulado foi de $6,86 \mu \mathrm{L} \pm 2,30(\mathrm{n}=60)$, e a concentração foi de $18,95 \% \pm 1,94(\mathrm{n}=60)$. A avaliação do volume e concentração do néctar de 2 em 2 horas

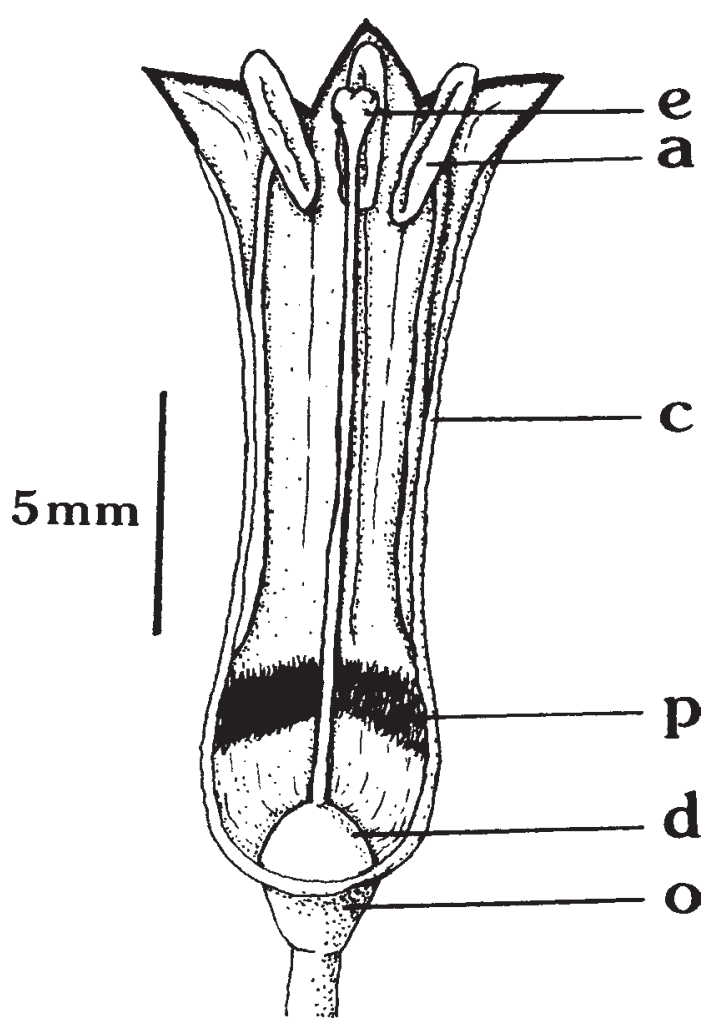

Figura 3. Desenho de um corte longitudinal da flor de Palicourea macrobotrys, mostrando os níveis de anteras e estigma $(\mathrm{e}=$ estigma, $\mathrm{a}=$ antera, $\mathrm{c}=$ corola tubular, $\mathrm{d}=$ disco nectarífero, $\mathrm{o}=$ ovário ínfero, $\mathrm{p}=$ pêlos).

Figure 3. Flower of Palicourea macrobotrys in a longitudinal view, showing the position of anther and stigma $(\mathrm{e}=$ stigma, $\mathrm{a}=$ anther, $\mathrm{c}=$ corolla tube, $\mathrm{d}=$ nectar disc, $\mathrm{o}=$ inferior ovary, $\mathrm{p}=$ trichomes). 
evidenciou uma produção irregular, no volume e, principalmente, na concentração (em equivalentes de sacarose) apresentando diferença significativa entre os intervalos avaliados (tabela 1), o que proporcionou ao visitante uma concentração irregular de açúcar ao longo do dia.

Todos os indivíduos da população estudada e todas as 21 flores das nove exsicatas de pelo menos cinco municípios diferentes nos estados de São Paulo e Mato Grosso, observadas nos herbários, mostraram anteras e estigma no mesmo nível dentro da flor, evidenciando a homostilia.

Foram registrados cinco visitantes de três grupos diferentes nas flores de Palicourea macrobotrys: duas espécies de beija-flores, duas de borboletas e uma de abelha (tabela 3).

A borboleta Heliconius erato phyllis F. foi freqüente somente quando as plantas apresentavam muitas flores disponíveis no auge da floração. Heliconius ethilla narcaea Godt. foi observada somente no final do segundo pico de floração, sendo que as duas espécies apresentaram comportamento semelhante na flor. Suas visitas foram longas e pouco freqüentes, restritas a um determinado indivíduo. Ao se aproximarem da planta, pousavam na corola e introduziam a probóscide no tubo, chegando a introduzir também a cabeça na entrada da corola. Suas visitas duravam até 30 segundos. Foram mais freqüentemente observadas entre 9:00 e 11:00 h, mas chegando até o período da tarde (tabela 4). Foram consideradas polinizadores ineficientes devido ao fato de tocarem os órgãos reprodutivos apenas em algumas visitas.

A abelha Ceratina sp. foi observada somente durante os picos de floração. Foi mais freqüente no fim da manhã e início da tarde e observada somente em um ou dois indivíduos de $P$. macrobotrys. Um número elevado de indivíduos mostrou o comportamento de entrar na corola e tentar coletar néctar. Foram observadas até duas abelhas dentro de uma mesma flor. O pólen não era utilizado como recurso, apesar de ser possível observar alguns grãos no corpo do inseto. Foram consideradas polinizadores ineficientes devido ao pequeno porte, não tocando nas partes reprodutivas, e também pela baixa freqüência das visitas.

O beija-flor Thalurania furcata foi o principal visitante (tabela 3 , figura 5), sendo observado desde a abertura das primeiras flores no início do período da floração. Suas visitas iniciavam-se no início da manhã e duravam até o anoitecer, sendo mais intensas no período da manhã, com visitas em intervalos de 40 minutos a uma hora; no período da tarde, efetuavam visitas a intervalos de até $2: 30 \mathrm{~h}$. A fêmea dessa espécie foi o principal visitante, sendo que o macho foi observado somente uma vez. Esse animal segue um modo de forrageamento do tipo "traplining" (Sazima et al. 1996), facilmente observado, já que visita indivíduos e flores na mesma seqüência e de forma semelhante durante todo o dia. A quantidade de pólen depositada no seu bico é muito grande e fácil de ser observada no campo. Todas as flores abertas no dia eram visitadas, mesmo aquelas que ficavam em inflorescências dispostas a poucos centímetros do chão. Essa espécie foi considerada como sendo o polinizador mais eficiente pois tocou os órgãos reprodutivos em todas as visitas.

O beija-flor Phaetornis pretrei foi observado somente após o segundo pico de floração, quando as flores, em menor número, proporcionavam um recurso mais escasso. A freqüência de suas visitas foi menor se comparado com T. furcata, mas com comportamento

Tabela 1. Volume, concentração e quantidade de açúcar em néctar coletado, durante um dia, em flores de Palicourea macrobotrys, na Estação Ecológica do Panga, Uberlândia, MG. Letras diferentes na mesma coluna indicam diferença significativa (KruskalWallis $\mathrm{p}<0,05)$.

Table 1. Nectar volume, concentration and sugar quantity during the lifetime of flowers of Palicourea macrobotrys, at Panga Ecological Station, Uberlândia, MG. Different letters in the same column indicate significant difference (Kruskal-Wallis $\mathrm{p}<0.05)$.

\begin{tabular}{|c|c|c|c|c|}
\hline Horário (h) & Volume $(\mu \mathrm{L})$ & Concentração (\%) & Peso açúcar $(\mathrm{g} / \mu \mathrm{L})$ & N. de flores \\
\hline 07:00 & $3,79 \pm 0,97 \quad \mathrm{a}$ & $20,19 \pm 1,24 \quad \mathrm{a}$ & $0,000827 \pm 0,000012$ & 20 \\
\hline 09:00 & $1,69 \pm 0,85 \quad b$ & $9,52 \pm 2,20 \quad a$ & $0,000166 \pm 0,000018$ & 20 \\
\hline 11:00 & $3,17 \pm 2,56 a b$ & $9,51 \pm 1,51 \quad b c$ & $0,000312 \pm 0,000038$ & 20 \\
\hline 13:00 & $1,34 \pm 0,74 \quad b$ & $10,32 \pm 2,32 \quad b$ & $0,000107 \pm 0,000017$ & 20 \\
\hline $15: 00$ & $0,52 \pm 0,21 \quad \mathrm{c}$ & $8,35 \pm 3,12 \quad b c$ & $0,000044 \pm 0,000006$ & 20 \\
\hline
\end{tabular}


Tabela 2. Resultados dos testes de polinizações controladas em Palicourea macrobotrys, na Estação Ecológica do Panga, Uberlândia, MG.

Table 2. Results of hand pollination tests in Palicourea macrobotrys, at Panga Ecological Station, Uberlândia, MG.

\begin{tabular}{lccc}
\hline Tratamento & $\begin{array}{c}\text { N. } \\
\text { flores }\end{array}$ & $\begin{array}{c}\text { N. } \\
\text { frutos }\end{array}$ & $\begin{array}{c}\text { Frutificação } \\
(\%)\end{array}$ \\
\hline Polinização cruzada & 51 & 39 & 76,47 \\
Autopolinização manual & 50 & 37 & 74,00 \\
Autopolinização espontânea & 56 & 36 & 64,28 \\
Apomixia & 50 & 2 & $4,00 *$ \\
Controle & 101 & 78 & 77,22 \\
\hline
\end{tabular}

* diferença significativa $\mathrm{x}^{2}$

semelhante, tocando os órgãos reprodutivos em todas as visitas. As duas espécies de beija-flores foram os principais visitantes (tabela 4), e não foram observadas visitando outras plantas no mesmo período e na mesma área, evidenciando fidelidade às flores de P. macrobotrys.

Não foi observado nenhum tipo de pilhador nas flores. Várias espécies de formigas percorriam toda a inflorescência, sem visitar as flores, visitando somente nectários já expostos pela queda da corola. Esses nectários ainda produziam néctar mesmo sem a corola, atraindo muitas formigas que patrulhavam a inflorescência.

Os tratamentos reprodutivos realizados indicaram que Palicourea macrobotrys é autocompatível e preferencialmente não apomítica, com alta produção de frutos tanto após polinizações manuais quanto após polinizações naturais (tabela 2). Testes estatísticos $\left(\mathrm{X}^{2}\right)$, indicaram que somente o tratamento de apomixia apresentou diferença significativa em relação a todos os outros tratamentos.

Em todos os pistilos observados, duas horas após as polinizações cruzadas ou autopolinizações, os tubos polínicos se encontravam na metade do estilete. Quatro horas após as polinizações (figura 4), os tubos polínicos já haviam alcançado o ovário e, após 6 horas, já haviam penetrado no ovário. Não foi possível observar o momento da penetração do tubo polínico no óvulo, devido ao grande acúmulo de tecidos nessa região, o que dificultou a observação.

\section{Discussão}

Palicourea macrobotrys apresentou padrão de floração do tipo extensiva (Bawa 1983), que se caracteriza por pequena produção diária de flores, por um período longo de até 7 meses. Padrão semelhante tem sido descrito para outras espécies de Rubiaceae, como P. rigida (Silva 1995), onde a espécie apresenta uma floração anual extensiva e com dois picos de intensidades diferentes. Espécies com floração "extensiva" minimizam o risco de florescer em períodos climáticos desfavoráveis ou de baixa disponibilidade de polinizadores, assegurando períodos favoráveis à reprodução (Grandisioli 1997).

De acordo com Augspurger (1983) o padrão fenológico de $P$. macrobotrys é intermediário, já que toda a população disponibiliza muitas flores por um longo período, mesmo apresentando picos de intensidades diferentes.

Tabela 3. Espécies de visitantes florais registrados em Palicourea macrobotrys, número total de visitas registradas e porcentagem de visitas na Estação Ecológica do Panga, Uberlândia, MG.

Table 3. Flower visitors, number and percentages of visits in Palicourea macrobotrys, at Panga Ecological Station, Uberlândia, MG.

\begin{tabular}{|c|c|c|c|c|}
\hline Ordem & Família & Espécie & Total de visitas & $\%$ \\
\hline \multicolumn{5}{|c|}{ Trochiliformes } \\
\hline & \multirow[t]{3}{*}{ Trochilidae } & Thalurania furcata (fêmea) & 342 & 57,57 \\
\hline & & Thalurania furcata (macho) & 14 & 2,36 \\
\hline & & Phaetornis pretrei & 17 & 2,87 \\
\hline \multicolumn{5}{|c|}{ Lepidoptera } \\
\hline & \multirow[t]{2}{*}{ Nymphalidae } & Heliconius ethilla narcaea & 128 & 21,54 \\
\hline & & Heliconius erato phyllis & 27 & 4,54 \\
\hline \multicolumn{5}{|c|}{ Hymenoptera } \\
\hline & Apidae & Ceratina sp. & 66 & 11,12 \\
\hline
\end{tabular}


Tabela 4. Visitantes florais de Palicourea macrobotrys e número de flores visitadas por intervalo de tempo, na Estação Ecológica do Panga, Uberlândia, MG.

Table 4. Frequency of flower visitors of Palicourea macrobotrys, at Panga Ecological Station, Uberlândia, MG.

\begin{tabular}{lccc}
\hline & \multicolumn{3}{c}{ Número de flores visitadas } \\
\cline { 2 - 4 } Horário & Beija-flores & Borboletas & Abelhas \\
\hline 6:00-8:00 & 97 & 37 & 2 \\
8:00-10:00 & 91 & 45 & 19 \\
10:00-12:00 & 94 & 31 & 13 \\
12:00-14:00 & 48 & 18 & 17 \\
14:00-16:00 & 22 & 13 & 7 \\
16:00-18:00 & 21 & 11 & 8 \\
Total & 373 & 155 & 66 \\
\hline
\end{tabular}

Inflorescências terminais como as de P. macrobotrys seguem o padrão mais comumente encontrado na família Rubiaceae (Robbrecht 1988). A posição terminal das inflorescências e das flores facilita o acesso e a retirada do néctar por beija-flores, que possuem o hábito de pairar durante a visita (Stiles 1978).

A espécie possui flores sem odor perceptível, mas com cores atrativas, onde a corola amarela contrasta com o eixo da inflorescência e o pedúnculo das flores vermelhos, semelhante ao observado em $P$. rigida (Silva 1995). Esse conjunto de cores, associado com a sincronia da floração pode estimular o deslocamento dos animais entre as plantas e exercer um papel importante na atração de beija-flores, pois esses animais enxergam cores desse espectro, aumentando as chances de polinização cruzada (Stiles 1985).

As flores de $P$. macrobotrys são tubulosas com lobos livres, dilatação da base da corola para acúmulo de néctar, parede do tubo da corola espessa, pêlos protetores internos que evitam a pilhagem de néctar por insetos pequenos, coloração conspícua e são nectaríferas. Essas características estão de acordo com os atributos florais predominantemente encontrados na síndrome de ornitofilia descrita por Faegri \& van der Pijl (1980), e têm sido observadas em vários outros estudos (Silva 1995, Sazima et al. 1996, Castro \& Oliveira 2001).

O volume de néctar produzido pelas flores de P. macrobotrys pode representar uma estratégia para que os polinizadores, que necessitam de mais recursos, visitem mais flores para se saciarem, incrementando a polinização cruzada. As recompensas florais devem ser suficientemente ricas para sustentar o metabolismo dos polinizadores, mas não para saciá-los, conservando-os, assim, em movimento entre as plantas da mesma espécie (Navarro 1999). O néctar é de suma importância na recompensa dos polinizadores e sua produção varia de acordo com o tamanho dos mesmos (Opler 1983, Cruden et al. 1983) e também com a biomassa floral (Opler 1983). A variação do volume e concentração do néctar observada durante o dia em $P$. macrobotrys pode ocorrer devido ao curto tempo de vida da flor. Testes estatísticos demonstraram diferenças significativas em períodos diferentes do dia, o que é evidenciado nas visitas observadas, que seguem um padrão semelhante ao da produção do néctar. Cruden et al. (1983) sugerem que a secreção de néctar é constante até que se alcance um volume crítico acumulado, quando é interrompida a produção. A diminuição do volume de néctar produzido já foi observada em flores que duram alguns dias (Cruden et al. 1983, Castro \& Oliveira 2001), indicando a exaustão de recursos no tecido nectarífero ou, até mesmo, a polinização já realizada. Após a queda da corola e das peças reprodutivas o nectário ficava exposto e continuava a produzir néctar, o que atraía muitas formigas que patrulhavam as inflorescências aproveitando o néctar produzido. Esse fato também foi observado em outras Rubiáceas, como Palicourea rigida (Silva 1995) e Tocoyena formosa (Santos \& DelClaro 2001).

Foi observado que a população de $P$. macrobotrys estudada é homostílica, mesmo pertencendo a um gênero cujas espécies são quase exclusivamente distílicas (Taylor 1997). Pode-se, entretanto, observar características de flores distílicas (longistílicas) nas flores de Palicourea macrobotrys, como menor superfície estigmática e grãos de pólen de tamanho maior e em menor quantidade. Essas características são bem semelhantes às de flores de indivíduos longistilícos do gênero Palicourea (Sobrevila et al. 1983, Ree 1997).

A homostilia no gênero Palicourea não é comum e foi citada somente para a espécie $P$. alpina (Sw.) DC. (Tanner 1982). Não se pode afirmar, ainda, com os dados disponíveis, que $P$. macrobotrys é homostílica, mesmo tendo sido encontradas nove populações homostílicas. É necessário observar outras populações, definindo a distribuição geográfica da espécie e verificando se a homostilia é característica da espécie como um todo, ou apenas de populações isoladas. Como já citado anteriormente, de acordo com Taylor (1997), quase todas as espécies de Palicourea até agora estudadas são distílicas devido a uma condição ancestral do gênero. Com isso, os dados de $P$. macrobotrys são de grande importância no estudo da evolução e variação 
de sistemas distílicos na família Rubiaceae e, principalmente, na tribo Psychotrieae.

A ornitofilia na família Rubiaceae foi registrada em vários trabalhos (Feinsinger et al. 1988, MarquesSouza et al. 1993, Passos \& Sazima 1995, Castro \& Oliveira 2001). No gênero Palicourea, a ornitofilia já foi descrita nos trabalhos de Sobrevila et al. (1983), Silva (1995) e Ree (1997), corroborando a hipótese de Taylor (1997), de que todas as espécies do gênero Palicourea são polinizadas por beija-flores.

Palicourea macrobotrys é polinizada quase exclusivamente por beija-flores confirmando suas características ornitófilas, como corola tubular, flores sem odor, cores fortes, disposição das flores na inflorescência e presença de néctar (Faegri \& van der Pij1 1980, Silva 1995, Sazima et al. 1996, Castro \& Oliveira 2001).

As duas espécies de beija-flores que visitaram as flores não as freqüentaram no mesmo período da florada. As duas espécies parecem seguir linhas de captura, não mostrando territorialidade (Sazima et al. 1996). Esse comportamento pode auxiliar maior fluxo de pólen entre os indivíduos e, conseqüentemente, maior sucesso reprodutivo, produzindo mais frutos e sementes, podendo manter a população estudada na área.

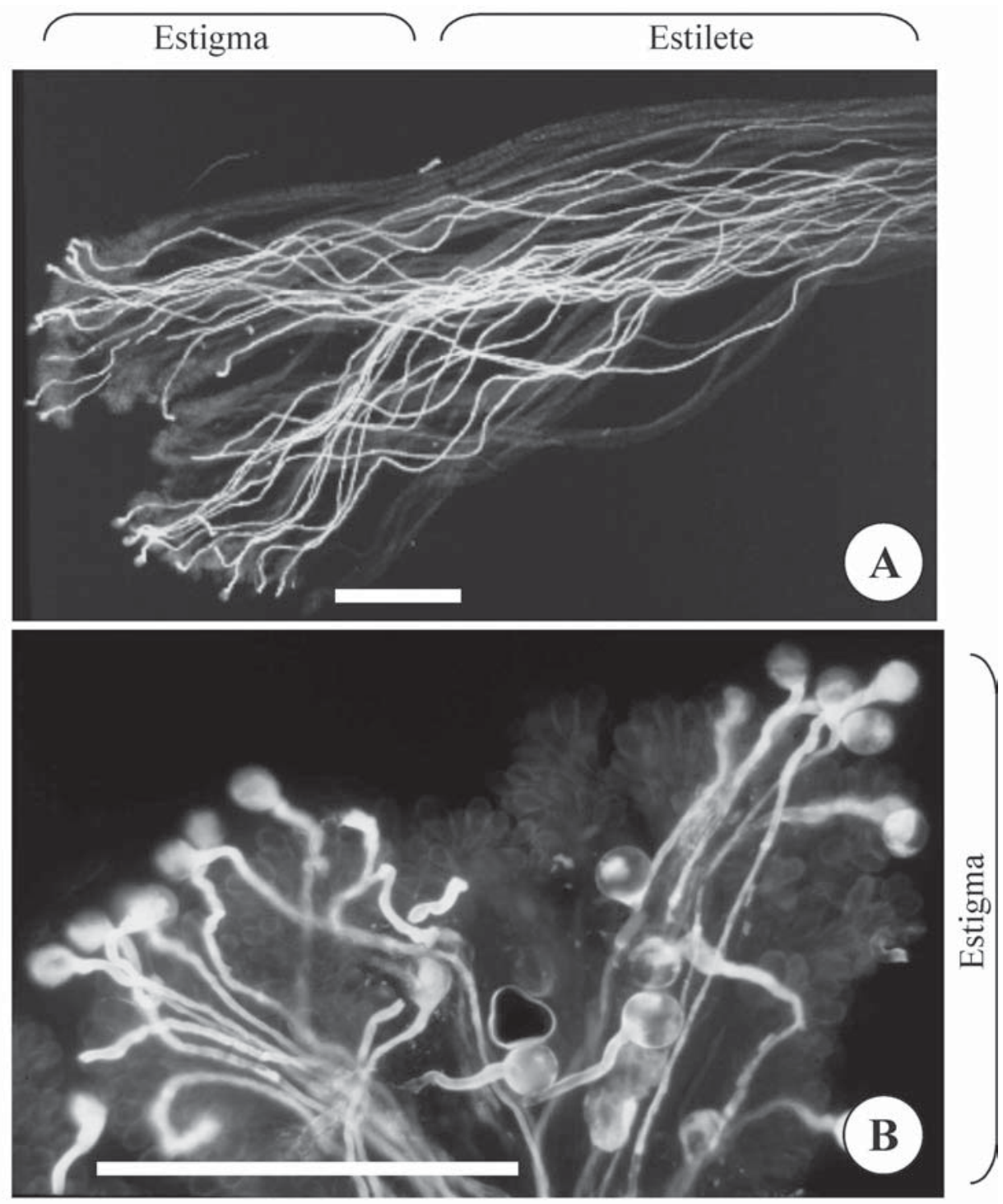

Figura 4. Crescimento de tubos polínicos em estigma e parte do estilete de Palicourea macrobotrys em flor autopolinizada, após quatro horas (barra $=1 \mathrm{~mm}$ ).

Figure 4. Pollen tube growth in stigma and upper style in P. macrobotrys, four hours after self-pollination (bar $=1 \mathrm{~mm}$ ). 


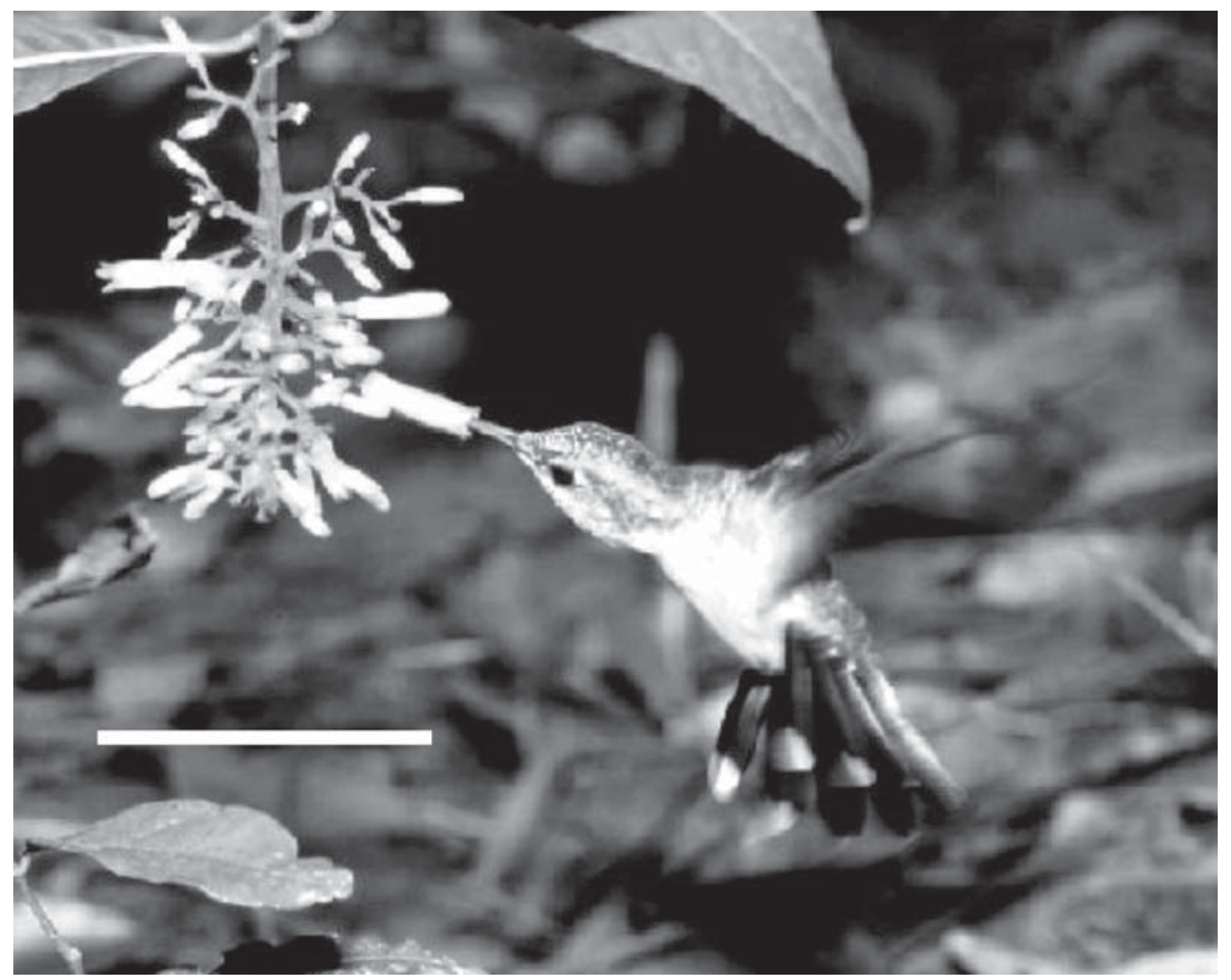

Figura 5. Fêmea de Thalurania furcata visitando flor de P. macrobotrys na Estação Ecológica do Panga, Uberlândia, MG (barra $=5 \mathrm{~cm})$.

Figure 5. A female individual of Thalurania furcata visiting flowers of P. macrobotrys in the Panga Ecological Station, Uberlândia, $\mathrm{MG}(\mathrm{bar}=5 \mathrm{~cm})$.

Com base na freqüência de visitas, comportamento e carga de pólen carregada, o beija-flor $T$. furcata (fêmea), foi considerado como a espécie mais importante no processo de polinização de P. macrobotrys. Os outros visitantes, borboletas e abelhas, mesmo não apresentando um comportamento legítimo nas visitas, pois tocavam os órgãos reprodutivos poucas vezes, podem ser considerados como polinizadores ocasionais.

A espécie em estudo apresentou, em todos os indivíduos analisados, somente flores com anteras e estigma em um mesmo nível. Nenhum sistema de incompatibilidade foi observado, e os frutos foram formados em todos os tratamentos excluindo apomixia. Com isso pode-se afirmar que essa população é totalmente homostílica, mas essa característica não pode, ainda, ser estendida para a espécie, devido à falta de estudos em populações de outros locais. No entanto esses dados corroboram, em parte, a hipótese de Taylor (1997), que considera que quase todas as espécies do gênero Palicourea são distílicas.

Avaliando a razão P:O encontrada, de acordo com Cruden (1977), esta espécie seria xenógama obrigatória, o que não foi confirmado. Mas esse resultado permite inferir que esta espécie pode ser distílica, pois espécies distílicas muitas vezes são xenógamas obrigatórias. Neste caso a espécie apresentaria somente algumas populações homostílicas, ou possuiria uma descendência próxima de uma espécie distílica, fazendo com que características ancestrais pudessem ser observadas.

Indivíduos homostílicos são interpretados como resultantes de "crossing-over" no supergene da heterostilia (Barrett \& Richards 1990). Vários autores já encontraram casos raros de indivíduos homostílicos dentro de populações distílicas de várias famílias, como Bir-Bahadur (1970a) para Pentas lanceolata (Forsk.) Delf., Bir-Bahadur (1968, 1970b) para Oldenlandia umbellata L., Crosby (1949) para Primula vulgaris 
Huds. e Pailler et al. (1998), para espécies do gênero Chassalia em ilhas na África. Segundo Bodmer (1960, apud Charlesworth \& Charlesworth 1979) a progênie de indivíduos homostílicos em grandes populações tem um baixo sucesso no estabelecimento, enquanto em populações pequenas esse sucesso pode ser bem maior e funcionar como uma estratégia no aumento populacional. Isso é interessante pois a fragmentação de hábitats pode afetar muito as populações distílicas, já que estas diminuem o número de indivíduos e proporcionam maior chance de indivíduos homostílicos aumentarem sua densidade.

Plantas homostílicas raramente são autoincompatíveis, coincidindo com o que foi observado na população estudada, onde só foram encontrados indivíduos homostílicos e autocompatíveis. A autocompatibilidade permite ampla distribuição geográfica e a ocupação de hábitats onde os polinizadores são escassos, ou onde o estabelecimento é, por algum motivo, comprometido (Ganders 1979, Barrett 1992). Essa autocompatibilidade impede o estabelecimento de seus parentes xenogâmicos exclusivos. A homostilia associada à autocompatibilidade pode estar presente na espécie estudada, talvez funcionando como uma estratégia para ocupar novos ambientes, aumentar as populações e manter a fecundidade.

Agradecimentos - Ao Dr. Paulo Eugênio A.M. Oliveira (Universidade Federal de Uberlândia) pelo auxílio e pela leitura crítica do manuscrito, à Dra. Sigrid L. Jung-Mendaçoli (Instituto Agronômico de Campinas) pela identificação do material vegetal, aos herbários da UEC e IAC por terem cedido material vegetal para análise, ao Dr. Kléber Del-Claro (Universidade Federal de Uberlândia) pela identificação das borboletas, à Dra. Maria Cristina Gaglione (USP - Ribeirão Preto) pela identificação das abelhas, aos Professores Drs. Christian Westerkamp e Peter E. Gibbs (Professores Visitantes - Universidade Federal de Uberlândia), pela ajuda nas discussões, e à Capes e Fapemig pelo auxílio financeiro.

\section{Referências bibliográficas}

AUGSPURGER, C.K. 1983. Phenology, flowering synchrony, and fruit set of six neotropical shrubs. Biotropica 15:257-267.

BAKER, H.G. 1958. Studies in the reproductive biology of West African Rubiaceae. Journal of the West African Science Association 4:9-24.

BARRETT, S.C.H. 1992. Evolution and function of heterostyly. Springer-Verlag, New York.
BARRET, S.C.H. \& RICHARDS, J.H. 1990. Heterostyly in tropical plants. Memoirs of the New York Botanical Garden 55:35-61.

BAWA, K.S. 1983. Patterns of flowering in tropical plants. In Handbook of experimental pollination biology (C.E. Jones \& R.J. Little, eds.). Scientific and Academic Editions, New York, p.394-410.

BIR-BAHADUR. 1968. Studies of natural populations in heterostylous Oldenlandia umbellata L. Journal of Genetics 60:80-97.

BIR-BAHADUR. 1970a. Heterostyly and homostyly in Pentas lanceolata (Forsk.) Delf. Journal of Genetics 60:199-204.

BIR-BAHADUR. 1970b. Homostyly and heterostyly in Oldenlandia umbellata L. Journal of Genetics 60:192-198.

CASTRO, C.C. \& OLIVEIRA, P.E.A.M. 2001. Reproductive biology of the protandrous Ferdinandusa speciosa Pohl (Rubiaceae) in Southeastern Brazil. Revista Brasileira de Botânica 24:167-172.

CHARLESWORTH, D. \& CHARLESWORTH, B. 1979. A model for evolution of heterostyly. American Naturalist 114:467-498.

CROSBY, J.L. 1949. Selection of an unfavourable gene complex. Evolution 3:212-230.

CRUDEN, R.W. 1977. Pollen-ovule ratios: a conservative indicator of breeding systems in flowering plants. Evolution 31:32-46.

CRUDEN, R.W., HERMAN, S.M. \& PETERSON, S. 1983. Patterns of nectar production and plant pollination coevolution. In The biology of nectaries (B. Bentley \& T. Elias, eds.). Columbia University Press, New York, p.80-125.

FAEGRI, K. \& VAN DER PIJL, L. 1980. The principles of pollination ecology. Pergamon Press, Oxford.

FEINSINGER, P., BUSBY, W.H. \& TIEBOUT III, H.M. 1988. Effects of indiscriminate foraging by tropical hummingbirds on pollination and plant reproductive success: experiments with two tropical treelets (Rubiaceae). Oecologia 76:471-474.

FOURNIER, L. 1974. Un método cuantitativo para la medición de características fenológicas en árboles. Turrialba 24:422-423.

GANDERS, F.R. 1979. The biology of heterostyly. New Zealand Journal of Botany 17:607-635.

GRANDISIOLI, E.A.C. 1997. Biologia reprodutiva e estrutura da população de Psychotria suterella Müll. Arg. (Rubiaceae) em um fragmento de mata secundária em São Paulo (SP). Dissertação de mestrado, Universidade de São Paulo, São Paulo.

GRANTSAU, R. 1989. Os beija-flores do Brasil. Expressão e Cultura, Rio de Janeiro.

HAMILTON, C.W. 1990. Variation on a distylous theme in Mesoamerican Psychotria subgenus Psychotria (Rubiaceae). Memoirs of the New York Botanical Garden 55:62-75. 
KEARNS, C.A. \& INOUYE, D.W. 1993. Techniques for pollination biologists. University Press of Colorado, Niwot.

KÖPPEN, W. 1948. Climatologia: com un estudio de los climas de la Terra. F.C.E., Ciudad de México.

MARQUES-SOUZA, A.C., ABSY, M.L., MIRANDA, I.P.D. \& KUCHMEISTER, H.E.C. 1993. Characteristics of flowers, nectar and visitors of Kerianthera preclara (Rubiaceae). Revista de Biologia Tropical 41:483-489.

MARTIN, F.N. 1959. Staining and observing pollen tubes in the style by means of fluorescence. Stain Technology 34:125-128.

NAVARRO, L. 1999. Pollination ecology and effect of nectar removal in Macleania bullata (Ericaceae). Biotropica 4:618-625.

OPLER, P.A. 1983. Nectar production in a tropical ecosystem. In The biology of nectaries (B. Bentley \& T. Elias, eds.). Columbia University Press, New York, p.30-79.

PAILLER, T., HUMEAU, L. \& FIGIER, J. 1998. Reproductive trait variation in the functionally dioecious and morphologically heterostylous island endemic Chassalia corallioides (Rubiaceae). Biological Journal of the Linnean Society 64:297-313.

PASSOS, L. \& SAZIMA, M. 1995. Reproductive biology of the distylous Manettia luteo-rubra (Rubiaceae). Botanica Acta 108:309-313.

REE, R.H. 1997. Pollen flow, fecundity and the adaptive significance of heterostyly in Palicourea padifolia (Rubiaceae). Biotropica 29:298-308.

RICHARDS, A.J. 1986. Plant breeding systems. George Allen \& Unwin, London.

ROBBRECHT, E. 1988. Tropical woody Rubiaceae. Opera Botanica Belgica 1:1-271.

ROSA, R., LIMA, S.C. \& ASSUNÇÃO, W.L. 1991. Abordagem preliminar das condições climáticas de Uberlândia (MG). Sociedade e Natureza 3:91-108.
SANTOS, J.C. \& DEL-CLARO, K. 2001. Interação entre formigas, herbívoros e nectários extraflorais em Tocoyena formosa (Cham. \& Schlechtd.) K. Schum. (Rubiaceae) na vegetação do cerrado. Revista Brasileira de Zoociências 3:77-92.

SAZIMA, M., BUZATO, S. \& SAZIMA, I. 1996. An assemblage of hummingbird-pollinated flowers in a montane forest in southeastern Brazil. Botanica Acta 109:149-160.

SILVA, A.P. 1995. Biologia reprodutiva e polinização de Palicourea rigida H.B.K. (Rubiaceae). Tese de mestrado, Universidade de Brasília, Brasília.

SOBREVILA, C., RAMIREZ, N. \& ENRECH, N.X. 1983. Reproductive biology of Palicourea fendleri and P. petiolaris (Rubiaceae) heterostylous shrubs of a tropical cloud forest in Venezuela. Biotropica 15:161-169.

STILES, F.G. 1978. Temporal organization of flowering among the hummingbird food plants of a tropical wet forest. Biotropica 10:194-210.

STILES, F.G. 1985. Seasonal patterns and coevolution in the hummingbird-flower community of a Costa Rican subtropical forest. Ornithology Monography 36:757-787.

TANNER, E. 1982. Breeding systems in a tropical forest in Jamaica. Biological Journal of the Linnean Society 18:263-278.

TAYLOR, C.M. 1989. Revision of Palicourea (Rubiaceae) in Mexico and Central America. Sistematic Botany Monography 26:1-102.

TAYLOR, C.M. 1997. Conspectus of the genus Palicourea (Rubiaceae: Psychotriae) with the description of some new species from Ecuador and Colombia. Annals of the Missouri Botanical Garden 84:224-262. 